\title{
On the stability of the atmosphere-vegetation system in the Sahara/Sahel region
}

\author{
Victor Brovkin, ${ }^{1}$ Martin Claussen, ${ }^{2}$ Vladimir Petoukhov, ${ }^{1}$ and Andrey \\ Ganopolski \\ Potsdam-Institut für Klimafolgenforschung, Potsdam, Germany
}

\begin{abstract}
A conceptual model has been developed for the analysis of atmospherevegetation interaction in subtropical deserts. The model can exhibit multiple stable states in the system: a "desert" equilibrium with low precipitation and absent vegetation and a "green" equilibrium with moderate precipitation and permanent vegetation cover. The conceptual model is applied to interpret the results of two climate-vegetation models: a comprehensive coupled atmosphere-biome model and a simple box model. In both applications, two stable states exist for the western Sahara/Sahel region for the present-day climate, and the only green equilibrium is found for the mid-Holocene climate. The latter agrees well with paleoreconstructions of Sahara/Sahel climate and vegetation. It is shown that for present-day climate the green equilibrium is less probable than the desert equilibrium, and this explains the existence of the Sahara desert as it is today. The difference in albedo between the desert and vegetation cover appears to be the main parameter that controls an existence of multiple stable states. The Charney's mechanism of self-stabilization of subtropical deserts is generalized by accounting for atmospheric hydrology, the heat and moisture exchange at the side boundaries, and taking into account the dynamic properties of the surface. The generalized mechanism explains the self-stabilization of both desert and vegetation in the western Sahara/Sahel region. The role of surface roughness in climate-vegetation interaction is shown to be of secondary importance in comparison with albedo. Furthermore, for the high albedo, precipitation increases with increasing roughness while, for the low albedo, the opposite is found.
\end{abstract}

\section{Introduction}

The study of the climate-vegetation interaction is a promising topic in climate system modeling, as this interaction could be crucial for the understanding of some climate phenomena. For example, the climate of the mid-Holocene, some $6 \mathrm{kyr}$ B.P. (6000 years before present) during which large parts of the Sahara were covered by vegetation [Hoelzmann et al., 1998] and boreal forests were found northward of their present-day limit, cannot be realistically modeled if the vegetationatmosphere feedback is omitted [Foley et al., 1994; Claussen and Gayler, 1997; Texuer et al., 1997; Kutzbach

\footnotetext{
${ }^{1}$ Also at Oboukhov Institute for Atmospheric Physics, Moscow, Russia.

${ }^{2}$ Also at Institut für Meteorologie, Freie Universität Berlin, Germany.
}

Copyright 1998 by the American Geophysical Union.

Paper number 1998JD200006.

0148-0227/98/1998JD200006\$09.00 et al, 1997]. Likewise, the cooling of the northern hemisphere during last glacial inception (some $115 \mathrm{kyr}$ B.P.) owing to changes in orbital forcing seems to have been strongly amplified by a southward shift of the northern boundary of the boreal forest [Gallimore and Kutzbach. 1996; de Noblet et al., 1996].

The energy balance model, introduced by Budyko [1969] and Sellers [1969] and developed in greater depth later on by Held and Suarez [1974], Ghil [1976], North et al. [1981], and Saltzman [1985], showed that a positive albedo-temperature feedback in the high latitudes could result in two different stable states: either an "icefree" or an "ice-covered" Earth. The one-dimensional radiative-equilibrium model by $\mathrm{Lr}$ et al. [1997] also yields two stable equilibria of vertical temperature profiles. The interesting question is whether the feedbacks between climate and vegetation could be strong enough to support the different steady states of the system on a regional or global level. A zero-dimensional model of climate-vegetation interaction by Svirezhev and von Bloh [1996] pointed to the possibility of the multiple equilibria in the system on a global level. In this model, vegetation cover has a low albedo, in contrast with bare soil or snow with a high albedo. 


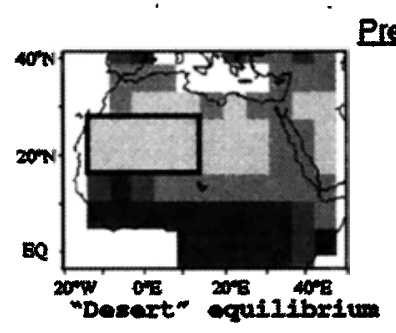

a)

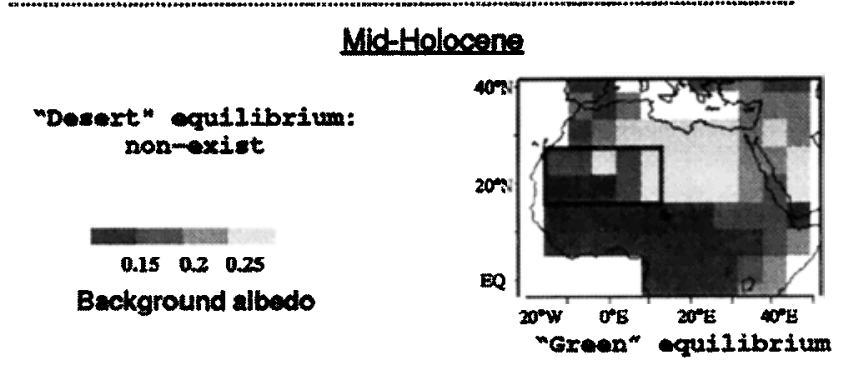

c)
Figure 1. The stable solutions obtained in ECHAMBIOME model for (a,b) present-day and (c) midHolocene in terms of background albedo. The solid line represents the areas where multiple equilibria solutions appear.

It is important that the multiple stable states phenomenon was detected not only in simple models but also in a comprehensive climate-biome model. When coupling the atmospheric general circulation model ECHAM, developed at the Max Planck Institute for Meteorology in Hamburg [Roeckner et al., 1992], with an equilibrium vegetation or the BIOME model by Prenlice et al. [1992], Claussen [1994, 1997, 1998] found that starting from different initial conditions the system comes to different climate-vegetation states in Sahara/Sahel region. Under present-day conditions of the Earth's orbital parameters and sea-surface temperature, two stable equilibria of vegetation patterns are possible. One solution corresponds to present-day sparse vegetation in the Sahel and deserted Sahara (desert equilibrium), the second solution yields savanna which extends far into the western part of the Sahara (green equilibrium). A similar picture is obtained for conditions during the last glacial maximum (LGM), 21 kyr B.P. [Kubatzkı and Claussen, 1998; Claussen et al., 1998]. For the mid-Holocene, however, the coupled model finds only one solution: the green Sahara [Claussen and Gayler, 1997]. The equilibria in terms of background albedo are shown in Figure 1.

One very important part of the biogeophysical feedback operating in the Sahara/Sahel region can be explained in terms of Charney's [1975] theory of selfstabilization of subtropical deserts due to their high albedo [see, also, Dickinson, 1982]. This theory treats desert as an isolated object and deals mainly with the radiative properties of the surface; for example, it does not explicitly take into account the hydrological cycle. Meanwhile, heat and moisture exchange at the boundaries (e.g., due to the summer monsoon from the At- lantic Ocean) play a rather important role in the climate of the West Sahara. Emanuel [1994] showed that the moist static energy and its fluxes are crucial quantities in moist atmospheres. According to Eltahir and Gong [1996], the meridional gradient of moist entropy (or moist static energy) between the land region and the Atlantic Ocean is the main factor determining the precipitation dynamics over West Africa. The budget of moist static energy in West Africa is analyzed and modeled by Zheng and Eltahir [1997].

If we study the multiple equilibria phenomenon from a mathematical point of view the most simple, or a conceptual model of the phenomenon must be a dynamical system of several key variables which play the main role in the interaction. In our paper, we first present a conceptual model, which deals with only two dynamic variables: one for vegetation and one for climate. This model is very simple, but it enables the multistable solutions to be represented. The advantage of the simple model lies in the possibility of understanding how basic physical mechanisms could work in more complex models; for detailed discussion of the usefulness of simple models in climate modeling see, for example, Ghal [1989]. Second, we demonstrate that this model is useful in the interpretation of results of comprehensive climate-vegetation model (ECHAMBIOME). Third, we apply the conceptual model for a simple box model of climate-vegetation interaction in subtropical deserts. That allows us to test the dependence of the multiple solutions in climate-vegetation system on internal (albedo and roughness) and external $\left(\mathrm{CO}_{2}\right.$ concentration in the atmosphere and insolation) parameters and extend Charney's [1975] analysis of the biogeophysical feedback in the Sahara/Sahel region.

\section{Conceptual Model of Atmosphere- Vegetation Interaction in Subtropical Desert in North Africa}

The dependence of vegetation on climate in subtropical deserts and semideserts can in a first approximation be expressed in terms of precipitation because the vegetation productivity is strictly limited by low water availability. Vegetation does not cover all the land surface, and between plants there is bare soil, sometimes covered with plant residues. The drier the climate is, the scarcer is the vegetation and the greater is the fraction of bare soil. Physical characteristics of bare soil (albedo, roughness, and water conductivity) differ from those of vegetation cover. That, in turn, creates a basis for the influence of vegetation on climate.

The subtropical region is under the strong influence of a downward branch of Hadley's circulation which causes low air humidity and low precipitation at all seasons except during the summer. In the summer season, Hadley's circulation over the region becomes weaker while the monsoon from the ocean brings moist air to the continents. Since precipitation in the subtropics depends upon these two counteracting factors, they are very sensitive both to external climate condi- 
tions (like insolation and zonally averaged circulation) and local factors (like land surface cover and sea surface temperature). We assumed that under fixed external climate conditions the precipitation $P$ over sufficiently large and homogeneous area in the subtropics depends only on the averaged vegetation fraction but not on specific types of vegetation cover. This assumption is justified by the fact that the physical characteristics of bare soil (albedo, roughness, and water conductivity) differ substantially from those for any type of vegetation.

By the vegetation fraction $V$ in a large area (comparable with the spatial resolution of general circulation models (GCMs)), we understand a fraction of land covered with any vegetation, at least during some season favorable to vegetation. The other fraction of land is the bare soil, or desert fraction. Generally, $V$ depends on both the temperature and precipitation factors, but within the narrow temperature interval we can neglect the temperature impact.

We write the interdependence of the two system variables, the vegetation fraction $V$ and precipitation $P$, in the general form of dynamic equations:

$$
\begin{aligned}
& \frac{d V^{\prime}}{d t}=W(V, P), \\
& \frac{d P}{d t}=Q(V, P, E),
\end{aligned}
$$

where $E$ are the external parameters (e.g., insolation and $\mathrm{CO}_{2}$ concentration in the atmosphere). The characteristic time of system variables, i.e., a time of system attraction to equilibrium, is different for variables $P$ and $V$. For precipitation, it is roughly several weeks, and, for vegetation, it is rather decades than years. Therefore, applying Tikhonov's theorem about the solution's dependence on a small parameter [see, e.g., Hubbard and West, 1995], we can separate the slow variable from the fast one and study the only dynamic equation for the slow variable, vegetation, in the vicinity of the equilibrium manifold for the fast variable, precipitation:

$$
Q(V, P, E)=0 \text {. }
$$

Let us suggest that for fixed $V$ and $E,(3)$ has unique solution $P=P^{*}(V, E)$. Than we can substitute it into (1)

$$
\frac{d V}{d t}=W\left(V, P^{*}(V, E)\right) .
$$

We use the common hypothesis that the vegetation distribution is mainly climate dependent [Holdridge, 1947; Woodward, 1987; Prentuce et al., 1992]; that is, the other environmental factors are of secondary importance. In our case that means that in equilibrium $V=V^{*}(P)$. Because we determine $V^{*}(P)$ as an equilibrium response to climate, the right part of (4) must depend on the difference of $V^{*}(P)-V$. The most simple dynamic equation which satisfies these rules is

$$
\begin{aligned}
\frac{d V}{d t} & =\frac{1}{\tau}\left(V^{*}(P)-V\right), \\
P & =P^{*}(V, E),
\end{aligned}
$$

where $\tau$ is a characteristic time of vegetation dynamics.

Equation (5) is consistent with the equation for dynamics of vegetation carbon, $C$ [see, e.g., Foley et al., 1994; Post et al., 1997], which can be written as

$$
\frac{d C}{d t}=N_{p}-m C
$$

assuming that $C$ and $V$ are monotonically interdependent, the mortality rate, $m$, is constant and the net primary productivity, $N_{p}$, depends on climate only [Lueth, 1975]; that is, in our case $N_{p}=N_{p}(P)$. It is interesting that (5), although in different terms, was already used by Gutman [1985].

The stability of the solutions of the system (equations (5) and (6)) is conveniently explored by using the Lyapunov functional [see, e.g., Drazın and Reıd, 1981] in the form:

$$
F(V, E)=-\int_{V_{0}}^{V^{*}} \frac{1}{\tau}\left(V^{*}\left(P^{*}(v, E)\right)-v\right) d v .
$$

Because $d F / d V=-d V / d t$, it follows from (5) that the minima of $F(V)$ represent the stable stationary solutions of the conceptual model (equations (5) and (6)), relative maxima the unstable stationary solutions.

Equations (5) and (6) are a dynamical system, which could be parameterized and solved explicitly. We are interested in the existence of multiple stable solutions. Therefore, instead of solving the system (equations (5) and (6)) explicitly, we will analyze the solutions of the equilibrium manifolds:

$$
\begin{aligned}
& V=V^{*}(P), \\
& P=P^{*}(V, E) .
\end{aligned}
$$

For this purpose, we use the convenient method of phase plane analysis. The equilibrium manifolds (9) and (10) are represented by curves on a phase plane (see Figure 2). In the following, we will seek parameterization for these dependencies.

The dependence of $V=V^{*}(P)$ in subtropical deserts obeys the following quite general rule: $V$ is near zero up to some threshold $P_{c r}$, then it grows fast, and finally approaches a saturation level $V=1$. The dependency $V=V^{*}(P)$ can be parameterized in different forms: for instance, in a logistic or hyperbolic form. This dependency is a potential one because $\tau$, a characteristic time of vegetation dynamics toward $V^{*}(P)$, ranges from years to decades. Precipitation, in turn, increases monotonically while $V$ increases. Generally, $P^{*}(V, E)$ is nonlinear, but, for simplicity, we show it as linear in Figure 2.

The points of intersection of the curves $V^{*}(P)$ and $P^{*}(V, E)$ in Figure 2 are the equilibria of the climatevegetation system. In the general case, the two curves intersect at either one or three points. The case of one intersection corresponds to one stable equilibrium in the climate-vegetation system. It could be either a desert equilibrium (case I) or a green equilibrium (case III). The case II shows three solutions, one of which (II*) 


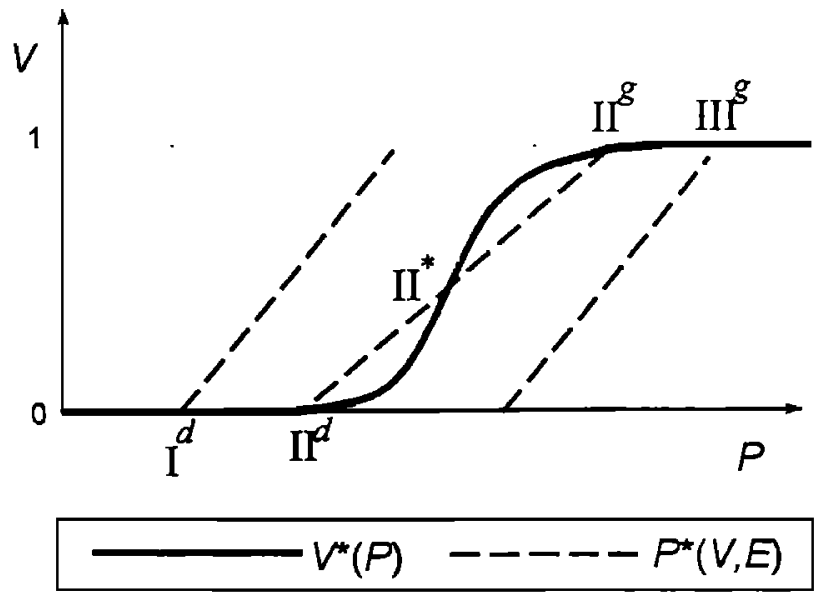

Figure 2. Schematic draft of the conceptual model. The solid curve represents the dependence of equilibrium vegetation on annual mean precipitation (equation (11)). The dashed line represents the linear model of precipitation as a function of vegetation cover. Cases I and III correspond to one equilibrium solution, desert $\mathrm{I}^{d}$ and green $\mathrm{III}^{g}$, respectively; case II corresponds to the stable desert $\mathrm{II}^{d}$ and green $\mathrm{II}^{g}$ equilibria as well as the unstable $\mathrm{II}^{*}$ solution.

appears to be unstable and separates the domains of attraction of the stable equilibria. The multiple equilibria case is relatively rare and could appear only under the specific conditions discussed below in section 4.3. The nongeneral, or degenerate, case of two intersection points of curves $V^{*}(P)$ and $P^{*}(V, E)$ corresponds to a saddle-node bifurcation.

\section{Interpretation of ECHAM-BIOME Results}

We use two data sets in our study, which are outputs of ECHAM-BIOME experiments [Claussen, 1997; Claussen and Gayler, 1997]. The first is the result of an experiment with the ECHAM3-T21 model (spatial resolution approximately $5.6^{\circ}$ ) for present-day climate, and the second is the result of an experiment with the ECHAM3-T42 model (spatial resolution approximately $2.8^{\circ}$ ) for the mid-Holocene climate, some $6 \mathrm{kyr}$ B.P. The climate model results are valid only on a large scale; therefore we used a study area equal to 10 cells of T21 resolution (see Figure 1) with the boundaries $16.8^{\circ}-27^{\circ} \mathrm{N}$ and $11.2^{\circ} \mathrm{W}-16.8^{\circ} \mathrm{E}$, equivalent to a size of about $1000 \times 2000 \mathrm{~km}$.

The BIOME model [Prentice et al., 1992] uses a climate-vegetation classification which operates with a high level of vegetation formations, namely biomes, for example tropical seasonal forest or savanna. From a mathematical point of view, this classification is discrete, as the number of biomes is finite. For one cell of the climate model, the discreteness of the vegetation description causes discrete dynamics of land-surface characteristics (albedo, roughness, vegetation fraction, etc.). Nonetheless, averaged over a large number of cells in a climate model, the response of land-surface characteristics to climate dynamics is much smoother than for one cell. That forced us to use the continuous function $V^{*}(P)$ for interpretation of the experiment's results.

The ECHAM-BIOME experiments were performed with the following methodology: (1) Initially, the North Africa biomes land cover was prescribed as either desert or tropical rain forest; (2) the climate model output was averaged for 5 years and the average climate was used as an input to BIOME to classify the new biome cover; (3) this new biome cover was fixed for the next 5-year experiment with the climate model; and (4) these iteration steps between ECHAM and BIOME were continued until equilibrium was achieved.

In the case of desert, the albedo of bare soil was prescribed in accordance with the soil texture: either "dark" desert with albedo 0.2 or sand desert with albedo 0.35 . An albedo of vegetation was prescribed at intervals from 0.12 for rain forest up to 0.2 for warm grass.

For present-day conditions, the initial conditions for desert were stable: The desert remained in the study area. The initial conditions for rain forest were not stable, and, after two iteration steps, the biomes distribution in the area was stabilized with a mixture of savanna, succulent woods, warm grass, and desert (see Figure 1). We call this stable branch of solution the green equilibrium because more than a half of the study area is covered by vegetation. In the green equilibrium, the precipitation is roughly 10 times greater than in the desert equilibrium.

The experiment with the climate conditions of midHolocene showed a very different system dynamics. The initial conditions for desert were characterized by a high level of precipitation $(235 \mathrm{~mm} / \mathrm{yr})$, and the desert was not stable. Started from initial conditions for desert, the system showed a step-by-step progression of vegetation into the study area. The important results which we can obtain from the latter experiment are the equilibrium responses curves $V^{*}(P)$ and $P^{*}(V, E)$. On a phase plane showing precipitation versus the vegetation fraction, we draw the points with the iteration results joined by arrows (see Figure 3). For every iteration step, except the initial one, there are two points

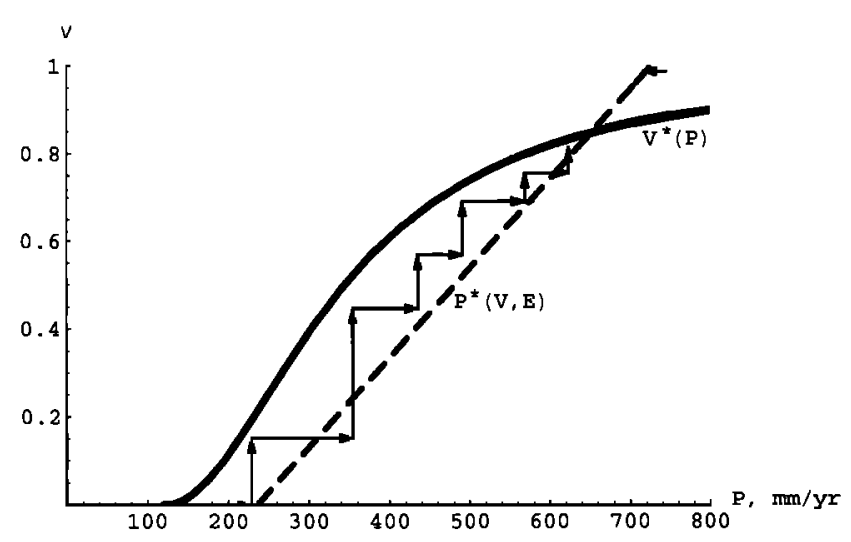

Figure 3. Results for mid-Holocene climate: interpretation of ECHAM-BIOME experiment. The iterations are shown by arrows. 
Table 1. Conceptual Model Parameters

\begin{tabular}{lccccccc}
\hline \multicolumn{1}{c}{ Model } & $P_{c r}$ & $a$ & \multicolumn{2}{c}{$P_{d}$} & & \multicolumn{2}{c}{$b$} \\
\cline { 7 - 8 } \cline { 7 - 8 } & & & Pres. & M-Hol. & & Pres. & M-Hol. \\
\hline ECHAM-BIOME & 120 & $2 \times 10^{-5}$ & 40 & 235 & & 590 & 500 \\
Box model & 60 & $5 \times 10^{-5}$ & 50 & 80 & & 360 & 420 \\
& & & & & & & \\
\hline
\end{tabular}

Pres. is the present-day climate and M-Hol. is the mid-Holocene climate (6.2 kyr B.P. for box model).

with the same precipitation. The vegetation fraction for these two points is different: One corresponds to precipitation from the present iteration and the second corresponds to precipitation from the previous iteration. If we fit the points, for instance, with a hyperbolic dependence for $V^{*}(P)$ and a linear dependence for $P^{*}(V, E)$, we get upper and lower boundaries of system dynamic trajectory, respectively. This method is similar to the so-called "stair step" or "Lamerey diagram" method which is used in dynamical system theory [see, e.g., Robınson, 1995; Svirezhev and Passekov, 1990]. Two curves intersect at the single point where precipitation is $660 \mathrm{~mm} / \mathrm{yr}$, which corresponds to the unique green equilibrium for mid-Holocene climate.

We use the hyperbolic curve for the $V^{*}(P)$ dependency:

$$
V^{*}(P)= \begin{cases}0 & \text { if } P<P_{c r} \\ 1-\frac{1}{1+a\left(P-P_{c r}\right)^{2}} & \text { otherwise }\end{cases}
$$

where $P_{c r}$ is a threshold value of annual mean precipitation below which no vegetation can exist in the long term. It is assumed that the evolution of plant species is a negligibly slow process and therefore these values are taken as invariable for the case of present-day climate. For $P^{*}(V, E)$ dependence we used the linear fit

$$
P^{*}(V, E)=P_{d}(E)+b(E) V,
$$

where $P_{d}$ is precipitation over desert. Some background for using the linear fit comes from the results of the

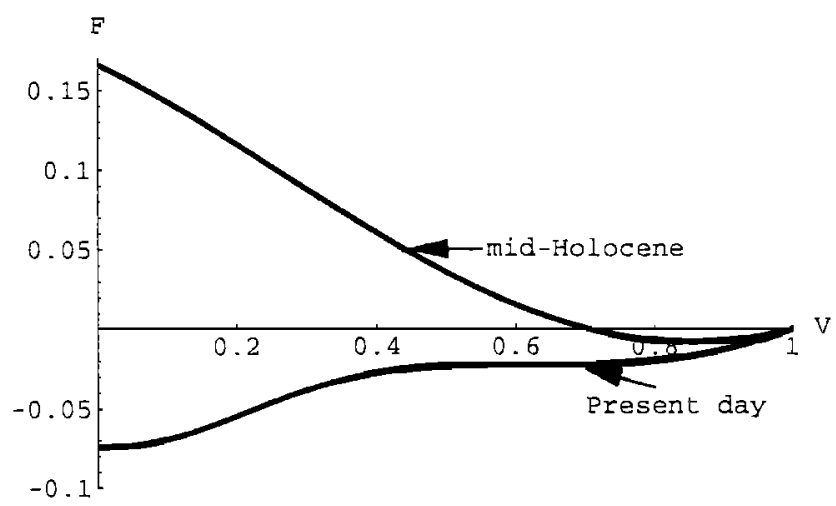

Figure 4. Lyapunov functional for present-day, midHolocene climates: interpretation of ECHAM-BIOME experiments. dynamic climate model, which is discussed in section 4.3. The values of parameters of (11) and (12), obtained by fitting of the ECHAM-BIOME results, are given in Table 1.

The curves $V^{*}(P)$ and $P^{*}(V, E)$ intersect three times for present-day climate and one time for mid-Holocene climate. Therefore, in terms of the conceptual model, present-day climate corresponds to three equilibria (case II in Figure 2), and the mid-Holocene corresponds to the unique green equilibrium (case III). The Lyapunov functional (equation (8)) reveals one minimum for the mid-Holocene but two for present-day climate (see Figure 4). Moreover, in Figure 4 the relative minimum corresponding to the green equilibrium for present-day is rather flat. Therefore any sufficiently large perturbation, for instance a prolonged drought such as is observed to occur at the decadal timescale [e.g. Lamb and Peppler, 1992], could take the system to the desert equilibrium.

\section{A Box Model of the Climate-Vegetation Interaction in the Western Sahara}

The results of the ECHAM-BIOME model provide us with a certain picture of the system behavior, but the high computational costs of the ECHAM model do not allow us to make an extensive analysis of results sensitivity to external and internal parameters. To get a tool for such an analysis, a box model of climatevegetation interaction in the Western Sahara has been designed. The box model is a realization of the conceptual model (equations (5) and (6)), where the dependency $V=V^{*}(P)$ is derived from the observed data of vegetation and climate in the Sahara/Sahel region and the dependency $P=P^{*}(V, E)$ is obtained from a simple dynamic model of climate in the region. With the box model, we analyze the system behavior for the present-day climate and the double $\mathrm{CO}_{2}$ climate and perform a transient experiment from the mid-Holocene to the present.

\subsection{A Vegetation Dependence on Climate in the Sahara/Sahel Region}

To obtain a dependence $V^{*}(P)$, we use the Olson et al. [1985] ecosystem map and the Leemans and Cramer [1991] climate data set following the approach 
of continuous vegetation description by Brovkin et al. [1997]. The main natural and seminatural ecosystems in North Africa are described by a fixed value of the vegetation fraction. We use "ad-hoc" values of the vegetation fraction: 0 for desert and semidesert, 0.3 for warm grass, 0.6 for succulent and thorn woods, 0.8 for dry and highland scrub, 1 for savanna, and 1 for forests. These values are similar to the values of the vegetation ratio presented by Claussen [1994]. To exclude the temperature factor, the vegetation fraction and the annual amount of precipitation are taken for land cells with an annual mean temperature in the interval between $25^{\circ}$ and $29^{\circ} \mathrm{C}$ (total area about $6 \times 10^{6} \mathrm{~km}^{2}$ ). The data for the vegetation fraction in response to precipitation are fitted to hyperbolic dependence (11). In terms of conceptual model, the values of parameters in (11) are different from those obtained by the ECHAM-BIOME interpretation (see Table 1), as they are valid for different vegetation descriptions and spatial scales.

\subsection{A Dynamic Model of Climate} in Subtropical Deserts

The climate model is developed only for the summer season because the rainfall in subtropical deserts takes place mainly at this time of the year. The summer climate in subtropical deserts is influenced mainly by the following dynamic patterns: Hadley circulation, zonal wind, local (e.g., monsoon) circulation, and convection. The influence of synoptic-scale activity, planetary scale quasi-stationary waves, centers of action, and near-equatorial systems of motion (e.g., Southern Oscillation and Kelvin waves) is ignored in a first approximation.

The atmosphere is presented by two layers: the planetary boundary layer (PBL) with the surface layer (SL) at its lower boundary and the free troposphere. The underlying land is represented by one soil layer. The main variables are the air temperature at the upper boundary of the PBL, $T_{B}$, and the specific humidity at the upper boundary of the SL, $q_{v s}$. The other variables are the zonal and meridional components of wind, vertical velocity, $w$, and pressure. Relative humidity at the upper boundary of the SL, $f_{s}$, cloudiness, $n$, intensity of rainfall, $P_{r}$, and mean annual precipitation, $P=\tau_{s} P_{r}$, where $\tau_{s}$ is summer season duration describe the hydrological cycle in the model.

All climate variables are divided into a zonal average (denoted by the overbars in the text) and deviation from this average. Zonal averages of climate variables as well as $T_{B}$ and $f_{s}$ at the side boundaries of the study area are specified in the model relevant to summer conditions of the present-day or other climate under consideration. Zonal averages of meridional and zonal winds represent the Hadley cell and zonal flow (in particular, the northern part of trade wind circulation). The deviations from the zonal averages of winds are attributed, in particular, to the monsoon-type circulations between the study area and adjacent oceanic and sea regions.

Ignoring heat and water storage in the atmosphere and soil, heat and water fluxes at the bottom of the soil layer, and run-off, the heat budget for the total unit column of the atmosphere-soil system is

$$
F_{\downarrow}^{S H}\left(1-A_{S Y}\right)-F_{\uparrow}^{T H}+A_{T}=\mathbf{0} .
$$

The first term in (13) is the solar radiation modified by the planetary albedo. It is a function of the insolation $I_{0}$, the mean solar zenith angle $\xi$, the cloudiness, and the albedo of the clouds and surface.

The term $F_{1}^{T H}$, net longwave radiation at the upper boundary of the system, is treated in accordance with Budyko [1982] as a function of the surface air temperature, cloudiness, and the $\mathrm{CO}_{2}$ concentration in the atmosphere $q_{r}$. Neglecting run-off from the area, the balance of the bulk atmospheric moisture content over the area is reduced to

$$
A_{q}=0 \text {. }
$$

The advective term $A_{T}$ in (13) and the advection of the atmospheric moisture $A_{q}$ are treated explicitly in accordance with Petoukhov [1980] and Petoukhov and Ganopolskl [1994].

Vegetation exerts an impact on climate through the surface albedo $A_{S}$ and surface roughness $z_{0} . A_{S}$ is supposed to depend linearly on $V$, while aggregation of $z_{0}$ is done by aggregation drag coefficients [Claussen, 1991], see (A14) and (A15).

The climate model is developed in two stages. First, the governing equations (13) and (14) were written for spatially distributed variables inside the area. As a result, all climate variables are expressed in terms of the prescribed zonal averages and $T_{B}$ and $q_{v s}$. The latter two main variables can be resolved from two governing equations at given boundary conditions. The solution to this boundary-value problem yields, finally, the nonlinear dependence $P=P^{*}\left(V, I_{0}, \xi, q_{c}, \lambda, \phi\right)$. Second, to perform a rather simple analytical treatment of the problem, the governing equations are averaged over the study area and rewritten in terms of area-averaged variables. The final analytical expression for $P^{*}\left(V, I_{0}, \xi, q_{c}\right)$ is given in the appendix (equations (A1)-(A15)).

The dynamic climate model is applied to the region of the Western Sahara (see Figure 1) using parameters listed in Table 2. The reference $\mathrm{CO}_{2}$ concentration in the atmosphere, $q_{c}^{0}$, is taken as an observed value for the year 1970 .

\subsection{Results for Present-Day Climate}

For an experiment with the present-day climate, the insolation $I_{0}$ and the solar zenith angle $\xi$ are taken as the present-day summer conditions (Table 2). The $\mathrm{CO}_{2}$ concentration in the atmosphere is equal to the reference concentration: $q_{c}=q_{c}^{0}$. The air humidity and temperature at the side boundaries are taken as observed for the adjacent oceanic and sea regions to the west (eastern Atlantic), north (Mediterranean basin), and south (equatorial Atlantic) and over the adjacent land region to the east of the study area (Table 2).

In Figure 5, the results of the calculation of $P$ as a function of $V$ are shown against the $V^{*}(P)$. One can see 
Table 2. Parameters of the Dynamic Climate Model

\begin{tabular}{|c|c|c|c|}
\hline Parameter & Term & Value & Units \\
\hline Air temperature at the top of the PBL at the side boundary & $T_{L}$ & 297 & $\mathrm{~K}$ \\
\hline Reference temperature & $T_{0}$ & 273.2 & $\mathrm{~K}$ \\
\hline Scale height for the atmosphere density & $H_{0}$ & $8.0 \times 10^{3}$ & $\mathrm{~m}$ \\
\hline PBL height & $h$ & $1.5 \times 10^{3}$ & $\mathrm{~m}$ \\
\hline Surface layer height & $z_{s}$ & 50 & $\mathrm{~m}$ \\
\hline Eddy diffusion coefficient in the PBL & $K_{0}$ & 60 & $\mathrm{~m}^{2} / \mathrm{s}$ \\
\hline Eddy diffusion coefficient in free atmosphere & $K_{T}$ & 14 & $\mathrm{~m}^{2} / \mathrm{s}$ \\
\hline Parameter of the Clausius-Clapeyron equation & $l_{0}$ & 0.622 & \\
\hline Latent heat of evaporation & $L$ & $2.5 \times 10^{6}$ & $\mathrm{~J} / \mathrm{kg}$ \\
\hline von Kärmän's constant & $\chi$ & 0.4 & \\
\hline Summer season duration & $T_{s}$ & $7.8 \times 10^{6}$ & s \\
\hline The Earth's radius & $a_{e}$ & $6.4 \times 10^{6}$ & $\mathrm{~m}$ \\
\hline Angular velocity of the Earth's rotation & $\omega$ & $7.4 \times 10^{-5}$ & $\mathrm{rad} / \mathrm{s}$ \\
\hline Reference specific humidity & $q_{0}$ & $3.8 \times 10^{-3}$ & \\
\hline Air gas constant & $R$ & 287 & $\mathrm{~m}^{2} /\left(\mathrm{s}^{2} \times \mathrm{K}\right)$ \\
\hline Adiabatic lapse rate & $\Gamma_{a}$ & $9.8 \times 10^{-3}$ & $\mathrm{~K} / \mathrm{m}$ \\
\hline Reference troposphere lapse rate & $\Gamma_{0}$ & $6.5 \times 10^{-3}$ & $\mathrm{~K} / \mathrm{m}$ \\
\hline Specific heat of air at constant pressure & $c_{p}$ & $1 \times 10^{3}$ & $\mathrm{~J} /(\mathrm{kg} \times \mathrm{K})$ \\
\hline Reference air density & po & 1.29 & $\mathrm{~kg} / \mathrm{m}^{3}$ \\
\hline Reference $\mathrm{CO}_{2}$ concentration in the atmosphere & $q_{c}^{0}$ & 325 & ppm \\
\hline $\mathrm{CO}_{2}$ sensitivity parameter & $\eta$ & 0.04 & \\
\hline Parameter of the Budyko equation & $A_{0}$ & 231 & $\mathrm{~W} / \mathrm{m}^{2}$ \\
\hline Parameter of the Budyko equation & $B_{0}$ & 2.1 & $\mathrm{~W} /\left(\mathrm{m}^{2} \times \mathrm{K}\right)$ \\
\hline Parameter of the Budyko equation & $C_{0}$ & 59 & $W / m^{2}$ \\
\hline Parameter of the Budyko equation & $D_{0}$ & 0.65 & $\mathrm{~W} /\left(\mathrm{m}^{2} \times \mathrm{K}\right)$ \\
\hline Cloudiness parameter & $\gamma_{0}$ & 180 & $\mathrm{~s} / \mathrm{m}$ \\
\hline Reference cloud amount & $n_{0}$ & 1.3 & \\
\hline Cloudiness albedo & $A c$ & 0.5 & \\
\hline Vegetation albedo & $A_{v}$ & 0.15 & \\
\hline Desert albedo & $A_{d}$ & 0.35 & \\
\hline Vegetation roughness & $z_{v}$ & 0.1 & $\mathrm{~m}$ \\
\hline Desert roughness & $z_{d}$ & 0.004 & m \\
\hline Blending height & $z_{b}$ & 100 & m \\
\hline Present-day summer insolation & $I_{0}$ & 1326 & $W / m^{2}$ \\
\hline Present-day mean summer daily cosine of zenith angle & $\cos \xi$ & 0.346 & \\
\hline Potential of zonal wind velocity & $U$ & $2.55 \times 10^{3}$ & $\mathrm{~m}^{2} / \mathrm{s}$ \\
\hline Potential of the Hadley velocity & $\Upsilon$ & $1.15 \times 10^{3}$ & $\mathrm{~m}^{2} / \mathrm{s}$ \\
\hline Mean zonal wind at the height of PBL & $|\bar{u}(h)|$ & 1.7 & $\mathrm{~m} / \mathrm{s}$ \\
\hline Longitude of the eastern boundary & $\lambda_{1}$ & 10 & ${ }^{\circ} \mathrm{W}$ \\
\hline Longitude of the western boundary & $\lambda_{2}$ & 15 & ${ }^{\circ} \mathrm{E}$ \\
\hline Latitude of the southern boundary & $\phi_{1}$ & 17 & ${ }^{\circ} \mathrm{N}$ \\
\hline Latitude of the northern boundary & $\phi_{2}$ & 28 & ${ }^{\circ} \mathrm{N}$ \\
\hline SL relative humidity at the western boundary & $f_{s, \lambda_{1}}$ & 0.8 & \\
\hline SL relative humidity at the eastern boundary & $f_{s, \lambda_{2}}$ & 0.3 & \\
\hline SL relative humidity at the southern boundary & $f_{s_{1} \phi_{1}}$ & 0.6 & \\
\hline SL relative humidity at the northern boundary & $f_{s_{1} \phi_{2}}$ & 0.8 & \\
\hline
\end{tabular}

in Figure 5 that two stable equilibria exist for present climate conditions, namely the desert equilibrium (as observed now) and the green equilibrium (vegetation covers more than $70 \%$ of the study area), depicted by points 1 and 2 , respectively. The unstable equilibrium (point 3) separates the domains of attractions of the desert and green solutions.

We test the model sensitivity to internal parameters. The slope of the curve $P=P^{*}(V, E)$ depends mainly on the difference in albedo between vegetation and desert. If the difference is small, the second equilibria does not exist. In none of the experiments with realistic boundary and initial conditions in the Western Sahara do we succeed in obtaining the second equilibrium if the albedo difference is less than 0.16 . If the lowest albedo value for the semidesert vegetation is fixed at 0.14 , then the multiple equilibria can be obtained only if the desert albedo is higher than 0.3 . That is possible only for nearoceanic sand deserts like the Sahara.

Let us point out that the dynamic climate model justifies a posteriori our suggestion that precipitation is significantly dependent on vegetation cover in the re- 


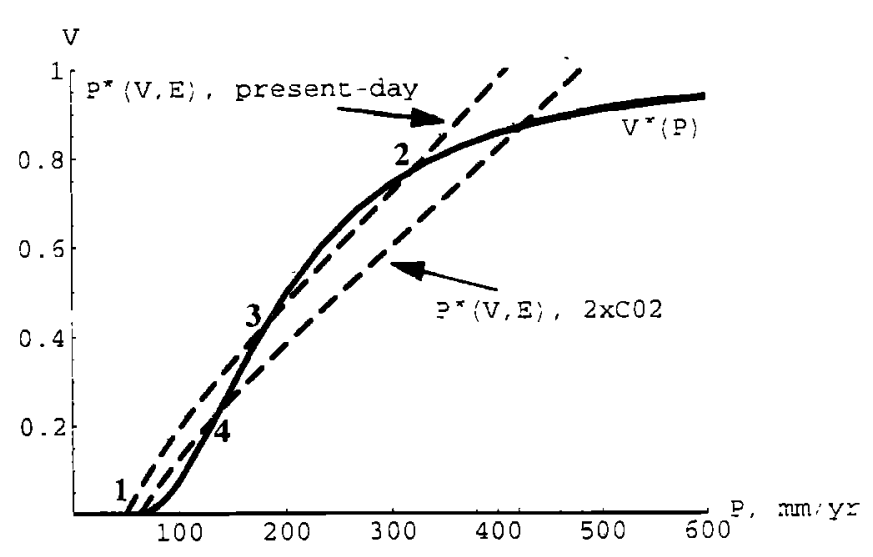

Figure 5. Results for present-day and double $\mathrm{CO}_{2}$ climates: box model.

gion, and this dependence has a nearly linear form (see Figure 5). Moreover, the parameters of the linearized dependence for the box model are numerically close to results of the ECHAM-BIOME model (see Table 1).

To get a deeper insight in the vegetation-atmosphere interaction, we analyze the sensitivity of precipitation to surface parameters: albedo and roughness. At any given constant roughness, an increase of albedo $A_{S}$ leads to decrease of precipitation (Table 3 ). This effect can be explained by Charney's theory (see Introduction): the higher the albedo is, the higher is the radiative sink in the system $\left(-R_{\text {net }}=-F_{\downarrow}^{S H}\left(1-A_{S Y}\right)+\right.$ $F_{\uparrow}^{T H}$ ), the lower are the temperature $T_{B}$, the vertical velocity, the cloudiness and, finally, the precipitation (see Table 3).

For the fixed albedo, the radiative sink $R_{\text {net }}$ in the system always decreases with increasing roughness,

Table 3. Sensitivity of Results of Dynamic Climate Model to Surface Albedo and Roughness

\begin{tabular}{|c|c|c|c|c|c|}
\hline \multirow[t]{2}{*}{ Variable } & \multicolumn{5}{|c|}{$A_{S}$} \\
\hline & 0.15 & 0.2 & 0.25 & 0.3 & 0.35 \\
\hline \multicolumn{6}{|c|}{$z_{0}=0.004($ Desert $)$} \\
\hline$P$ & 430 & 315 & 207 & 115 & 49 \\
\hline$R_{\text {net }}$ & -404 & -422 & -446 & -477 & -514 \\
\hline$T_{B}-T_{L}$ & 6.1 & 5.6 & 5.0 & 4.2 & 3.2 \\
\hline$w$ & 3.35 & 3.13 & 2.86 & 2.52 & 2.08 \\
\hline$n$ & 0.77 & 0.66 & 0.54 & 0.40 & 0.27 \\
\hline$f_{s}$ & 0.61 & 0.57 & 0.52 & 0.46 & 0.38 \\
\hline \multicolumn{6}{|c|}{$z_{0}=0.1$ (Vegetation) } \\
\hline$P$ & 410 & 311 & 212 & 123 & 54 \\
\hline$R_{\text {net }}$ & -394 & -410 & -434 & -466 & -506 \\
\hline$T_{B}-T_{L}$ & 3.0 & 2.8 & 2.5 & 2.1 & 1.6 \\
\hline$w$ & 3.46 & 3.25 & 2.98 & 2.64 & 2.18 \\
\hline$n$ & 0.83 & 0.72 & 0.59 & 0.45 & 0.29 \\
\hline$f_{s}$ & 0.63 & 0.59 & 0.54 & 0.48 & 0.40 \\
\hline
\end{tabular}

Units are $P, \mathrm{~mm} / \mathrm{yr} ; R_{\text {net }}, \mathrm{J} / \mathrm{m}^{-2} ; T_{B}-T_{L}, \mathrm{~K} ; w, 10^{-3}$ $\mathrm{m} / \mathrm{s}$; and $z_{0}, \mathrm{~m}$ while the precipitation response to roughness change is more complex. For the high albedo, the precipitation increases with increasing roughness, but, for the low albedo, the tendency is the opposite (see Table 3 ). Precipitation is computed as a function of the mean air temperature at the top of the PBL, $T_{B}$, the cloudiness, $n$, the vertical velocity at the top of the PBL, $w(h)$, and the relative humidity, $f_{s}$ (see (A1)). The parameters $n, w(h)$, and $f_{s}$ increase with the increasing $z_{0}$, but $T_{B}$ decreases. Simultaneous increase of $w(h)$ and decrease of $T_{B}$ with increasing $z_{0}$ is the consequence of the increase of the cross-isobar angle, which leads to the intensification of the monsoon-type circulation over the region.

Let us note that the increase of $V$ is accompanied by the simultaneous decrease of $A_{S}$ and increase of $z_{0}$. Owing to more pronounced influence of the $A_{S}$ on $P$ (see Table 3), the increase of $P$ with increasing $V$ is accompanied by the increase of $R_{\text {net }}$, i.e., by a decrease of the radiative sink in the system.

\subsection{Results for Double $\mathrm{CO}_{2}$ Climate}

To study the impact of $\mathrm{CO}_{2}$ on the climate in the area, an experiment for doubled preindustrial $\mathrm{CO}_{2}$ concentration $(560 \mathrm{ppm})$ is undertaken. The temperature $T_{L}$ is taken as $2 \mathrm{~K}$ higher than for the present-day, in order to account for the mean zonal warming. The other parameters are the same as for present-day climate (see Table 2).

One can see from the results in Figure 5 that as for present-day climate two stable equilibria exist in the system, but, for the double $\mathrm{CO}_{2}$ climate, the $P=$ $P^{*}(V, E)$ curve shifts to the right (more precipitation $P$ at a given $V$ ), and it is steeper (has a larger value of $\partial P / \partial V)$ than for present climate. The unstable equilibrium for the double $\mathrm{CO}_{2}$ climate (point 4) is located at value $V$, which is less than for present-day climate. Therefore the probability of the realization of the green equilibrium increases with the increasing $\mathrm{CO}_{2}$ content of the atmosphere.

Figure 6 depicts the Lyapunov functional $F(V, E)$ (see (8)). The functional $F(V, E)$ reveals two minima for present-day and double $\mathrm{CO}_{2}$ climate. Moreover, the

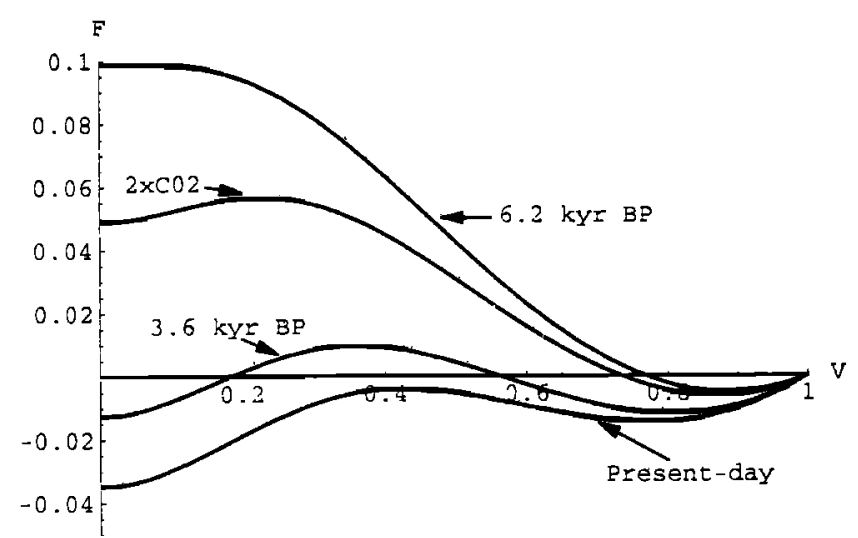

Figure 6. Lyapunov functional for present-day, $3.6 \mathrm{kyr}$ B.P. and 6.2 kyr B.P. climate: box model. 
minimum corresponding to the desert equilibrium for the present-day is lower than the minimum of the green equilibrium. The inverse picture is valid for the double $\mathrm{CO}_{2}$ climate: The minimum for green equilibrium is lower than that for the desert equilibrium.

The increase of $P$ for the double $\mathrm{CO}_{2}$ climate in comparison with the present-day conditions can be explained by the simultaneous increase of the main precipitation driving parameters $T_{B}-T_{L}, w(h), n, f_{s}$, and $T_{B}$ (see (A1)). The $T_{B}-T_{L}$ difference and therefore $w(h)$ are higher due to a specific feature of the greenhouse effect [see, e.g., Houghton et al., 1992]: Over the land regions with relatively high surface albedo and low humidity, this effect is higher than over the adjacent ocean regions. Let us note that $T_{B}$ is higher due to the higher side boundary temperature $T_{L}$, and $n$ is higher due to the higher air humidity at the side boundaries.

\subsection{Results for Paleoclimate}

In order to analyze the system dynamics in the Western Sahara during the Holocene, the transient experiment is undertaken with the box model. The dynamics of main climate forcings, $I_{0}(t), \xi(t)$, and $q_{c}(t)$ are taken into account. Insolation and solar zenith angle in the past are calculated, based on the dynamics of the Earth's orbital parameters (eccentricity, perihelion, and obliquity) in accordance with Berger $[1978,1996]$. The dynamics of $\mathrm{CO}_{2}$ in the atmosphere are taken from the ice core studies [Barnola et al., 1993; Neftel et al., 1993]. The boundary conditions, including air temperature and humidity, are prescribed by present climate values. Moreover, we assume that the vegetation dynamics are always faster than the dynamics of external forcing and therefore the vegetation is always in quasiequilibrium with climate, or $V=V^{*}(P)$.

The dynamics of system solutions in terms of precipitation $P=P^{*}\left(V, I_{0}(t), \xi(t), q_{c}(t)\right)$ from the early Holocene to present day are presented in Figure 7. The two stable branches of the solution, the green branch with relatively high precipitation and the desert branch with low precipitation (see Figure 7), are separated by the unstable branch. In the early Holocene, some 10

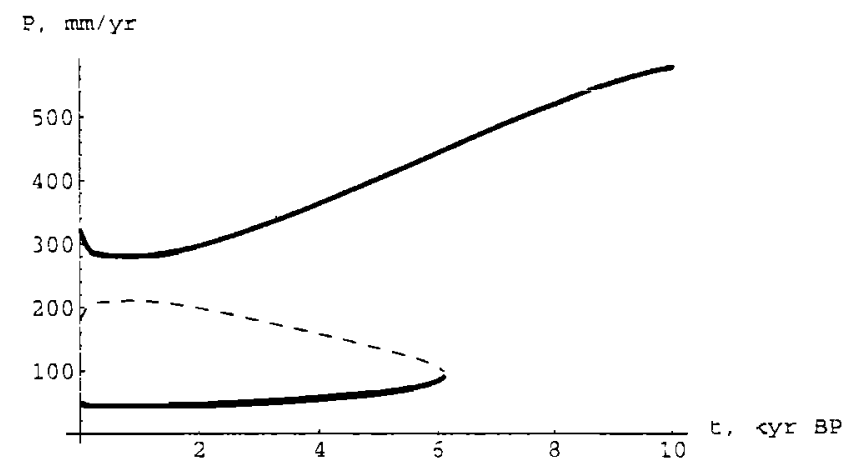

Figure 7. Dynamics of system solution in terms of precipitation $P$ during the last $10 \mathrm{kyr}$. The top line is the green branch of the solution; the bottom line is the desert branch of the solution; the dashed line represents the unstable branch of the solution. kyr ago, only the green equilibrium existed in the area with annual precipitation about $600 \mathrm{~mm} / \mathrm{yr}$. Owing to decreased summer insolation, the precipitation declined to $400 \mathrm{~mm} / \mathrm{yr}$ at the end of mid-Holocene, and the stable desert equilibrium appeared (about 6 kyr B.P. in the model). The impact of solar insolation on precipitation in the model is similar to the impact of $\mathrm{CO}_{2}$ concentration in the atmosphere discussed above.

It is interesting to estimate when the green equilibrium was replaced by the desert equilibrium during the late Holocene. The dynamic climate model, due to its simplicity, can reproduce only abrupt changes in climate which correspond to a switch from one solution branch to another. To assess when this switch could occur in the model, the Lyapunov functional is calculated and is presented for several time slices in Figure 6. In Figure 6, the equilibria correspond to the minima of the functional. For 6.2 kyr B.P., there is the only minimum that corresponds to green equilibrium. For present days, there are two minima: The desert equilibrium is at an absolute minimum and the green equilibrium is at a relative minimum. Some $3.6 \mathrm{kyr}$ B.P. both equilibria have the same values of the Lyapunov functional (see Figure 6). In this sense, the green equilibrium became less stable than desert equilibrium after $3.6 \mathrm{kyr}$ B.P. More precisely, the switch from one solution branch to another depends on the possibility for the system to "jump" over the maximum which separates the two minima in Figure 6. The real system always has some degree of stochastic behavior because of the variability of external forcing. The switch from one solution to another becomes possible if the variability of the Lyapunov functional becomes compatible with the height of maximum. Moreover, this switch could be initiated by changes in vegetation cover, caused, for example, by anthropogenic activity (cropland degradation and pasture overgrazing). Therefore the correct study of the system transition requires an application of a dynamic model, which has to take into account the high variability of precipitation in the area, the characteristic timescale of the response of vegetation to climate change, and anthropogenic impact. The development of such a model is beyond the scope of this paper.

\section{Conclusions}

A coñceptual model has beeñ develóped fór the analysis of atmosphere-vegetation interaction in subtropical deserts. On the basis of the vegetation-precipitation feedback, the conceptual model can exhibit multiple stable states in the system: a desert equilibrium with low precipitation and absent vegetation and a green equilibrium with moderate precipitation and permanent vegetation cover. The conceptual model is applied for interpretation of the results of two climate-vegetation models: a comprehensive coupled atmosphere-biome model and a simple box model. In both applications, two stable states exist for the Western Sahara/Sahel region for the present-day climate, and the only green equilibrium is found for the mid-Holocene climate. In the terms of the Lyapunov functional, the relative min- 
imum corresponding to the green equilibrium is rather flat for present-day climate. Any sufficiently large perturbation of the atmosphere-vegetation system in the Sahara/Sahel region could, in principle, push the potentially green Western Sahara into a desert condition. This would explain the existence of the Sahara desert as it is today, in spite of the fact that the ECHAMBIOME model, as well as the box model, predicts that a green Western Sahara is possible as well.

Charney's mechanism of selfstabilization of subtropical deserts is generalized by accounting for atmospheric hydrology, the heat and moisture exchange at the side boundaries, and dynamic properties of the surface. The generalized mechanism explains the self-stabilization of both desert and vegetation in the Western Sahara/Sahel region. We have studied the sensitivity of the multiple equilibria phenomenon to surface albedo and roughness. The slope of curve $P^{*}(V, E)$ depends mainly on the difference in albedo between vegetation and desert. If the difference is small, the second equilibria does not exist. The role of surface roughness in climate-vegetation interaction is found to be of secondary importance in comparison with albedo, while roughness could modify the precipitation in the opposite direction than albedo.

In experiments with the box model for double $\mathrm{CO}_{2}$ concentration in the atmosphere, the precipitation for a given vegetation fraction in Western Sahara increases. Therefore the probability of the occurrence of more vegetated spots in the region increases with the increasing $\mathrm{CO}_{2}$ content in the atmosphere.

The box model is used for analysis of the stability of the atmosphere-vegetation system in the Western Sahara during the transition from the Holocene to the present-day under external forcing by insolation and $\mathrm{CO}_{2}$ concentration in the atmosphere. In the early Holocene, some $10 \mathrm{kyr}$ ago, only the green equilibrium existed in the region. Because of decreased summer insolation, the precipitation declined, and the stable desert equilibrium appeared about 6 kyr B.P. Some 3.6 kyr B.P., both equilibria had the same values of the Lyapunov functional, and, in this sense, the green equilibrium became less stable than desert equilibrium after $3.6 \mathrm{kyr}$ B.P.

The presented models cannot, of course, prove the existence of multiple solutions of the atmosphere-vegetation system. However, they provide a consistent picture by predicting the stability of the equilibrium solutions.

\section{Appendix: Equations of the Dynamic Climate Model}

$$
\begin{gathered}
P=\rho_{0} \tau_{s} w(h) n q_{s}\left(T_{B}\right) f_{s}, \\
n=x^{2}\left(1+\gamma_{0} w(h)\right), \\
f_{s}=\frac{x}{n_{0}^{\frac{1}{2}}}, \\
w(h)=\frac{\delta R_{h}\left(T_{B}-T_{L}\right)-\Upsilon}{\Delta_{s}}+\frac{K_{T}}{H_{0}},
\end{gathered}
$$

$$
T_{B}=T_{L}+\frac{x}{n_{0} \frac{1}{2} b_{2}}-\frac{b_{1}}{b_{2}}
$$

where

$$
\begin{aligned}
& x=\frac{-b_{x}+\left(b_{x}^{2}+4 a_{x} c_{x}\right)^{\frac{1}{2}}}{2 a_{x}}, \\
& a_{x}=I_{0} \cos \xi\left(A_{C}-A_{S}\right)-\eta_{c}\left(C_{0}+D_{0} T_{c}\right), \\
& b_{x}=\frac{\Delta_{s} \eta_{c} B_{0}+\delta R_{h} c_{p} \rho_{0} H_{0}\left(\Gamma_{a}-\Gamma_{0}\right)}{\Delta_{s} n_{0} \frac{1}{2} b_{2}}, \\
& c_{x}=I_{0} \cos \xi\left(1-A_{S}\right)-\eta_{c}\left[A_{0}+B_{0}\left(T_{c}-\frac{b_{1}}{b_{2}}\right)\right] \\
& +\frac{c_{p} \rho_{0} H_{0}}{\Delta_{s}}\left(\Gamma_{a}-\Gamma_{0}\right)\left(\delta R_{h} \frac{b_{1}}{b_{2}}+\Upsilon\right), \\
& b_{1}=\frac{f_{s, \lambda 2} U+f_{s, \lambda 1} \Upsilon \frac{h}{H_{0}}}{U+\sigma_{\lambda, \phi} \Upsilon}, \\
& b_{2}=\frac{R_{h}}{U+\sigma_{\lambda, \phi} \Upsilon} \sum_{i=1}^{2}\left(f_{s, \lambda_{2}}\right. \\
& \left.+\sigma_{\lambda, \phi} \cos \bar{\phi} \cdot f_{s, \phi_{i}} \cos \phi_{l}\right) \text {, } \\
& R_{h}=\frac{h R}{f_{0} \sigma_{\lambda} a_{\varepsilon} \cos \bar{\phi}} \sin \alpha_{o s}, \\
& \sin \alpha_{o s}=\left[2+\left(2\left|f_{0}\right| K_{0}\right)^{\frac{1}{2}} \frac{\ln ^{2} \frac{z_{\mathcal{S}}}{z_{0}}}{\chi^{2}|\bar{u}(h)|}\right]^{-1}, \\
& A_{S}=V A_{v}+(1-V) A_{d}, \\
& \left(\ln ^{2} \frac{z_{b}}{z_{0}}\right)^{-1}=V\left(\ln ^{2} \frac{z_{b}}{z_{v}}\right)^{-1}+(1-V)\left(\ln ^{2} \frac{z_{b}}{z_{d}}\right)^{-1},
\end{aligned}
$$

where $U=\int_{0}^{\infty} e^{\frac{-z}{h}}|\bar{u}| d z, \Upsilon=\int_{0}^{h} \cos \phi_{1}|\bar{v}| d z, q_{s}\left(T_{B}\right)=$ $q_{0} e^{\left(l_{0} L / R\right)\left(T_{B}-T_{0}\right) /\left(T_{B} T_{0}\right)}, T_{c}=T_{L}-T_{0}, f_{0}=2 \omega \sin \bar{\phi}$ $\eta_{c}=\left(1-\eta \ln \frac{q_{c}}{q_{c}^{0}}\right), \Delta_{s}=a_{e} \sigma_{\phi} \cos \bar{\phi}, \delta=2 / \sigma_{\lambda, \phi}+$ $\sigma_{\lambda, \phi} \cos \bar{\phi} \sum_{i=1}^{2} \cos \phi_{i}, \bar{\phi}=\left(\phi_{1}+\phi_{2}\right) / 2, \sigma_{\lambda, \phi}=\sigma_{\lambda} / \sigma_{\phi}$, $\sigma_{\lambda}=\left(\lambda_{2}-\lambda_{1}\right) /(2 \pi)$, and $\sigma_{\phi}=\left(\phi_{2}-\phi_{1}\right) /(2 \pi)$.

Acknowledgments. The authors thank Yuri Svirezhev, Potsdam-Institut für Klimafolgenforschung (PIK), for helpful comments and Alison Schlums, PIK, for editing the manuscript.

\section{References}

Barnola, J.M., D. Raynaud, C. Lorius, and Y.S. Korotkevich, Historical $\mathrm{CO}_{2}$ record from the Vostok ice core, in Trends '93: A Compendium of Data on Global Change, Carbon Dioxide Info. Anal. Cent., Oak Ridge Natl. Lab., Oak Ridge, Tenn., 1993.

Berger, A.L., Long-term variations of daily insolation and 
Quaternary climatic changes, J. Atmos. Scı., 35, 23622367,1978

Berger, A., Orbital variations, in Encyclopedia of Climate and Weather, edited by S. Schneider, pp. 557-564, Oxford Univ. Press, New York, 1996.

Brovkin, V., A. Ganopolski, and Y. Svirezhev, A continuous climate-vegetation classification for use in climatebiosphere studies, Ecol. Modell., 101, 251-261, 1997.

Budyko, M.I., The effect of solar radiation variations on the climate of the Earth, Tellus, 21, 611-619, 1969.

Budyko, M.I., The Earth's Climate: Past and Future, 307 pp., Academic, San Diego, Calif., 1982.

Charney, J.G., Dynamics of deserts and drought in the Sahel, Q.J. R. Meteorol. Soc., 101, 193-202, 1975.

Claussen, M., Estimation of areally-averaged surface fluxes, Boundary Layer Meteorol., 54, 387-410, 1991.

Claussen, M., On coupling global biome models with climate models, Clim. Res., 4, 203-221. 1994.

Claussen, M., Modeling biogeophysical feedback in the African and Indian Monsoon region, Climate Dyn., 13, 247-257, 1997

Claussen, M., On multiple solutions of the atmospherevegetation system in present-day climate, Global Change Brol., f, 549-559, 1998 .

Claussen. M., and V. Gayler, The greening of Sahara during the mid-Holocene: Results of an interactive atmospherebiome model, Global Ecol. and Biogeography Lett., 6, 369$37 \tau, 1997$.

Claussen, M.. U. Lohmann, E. Roeckner, and U. Schulzweida, A global data set of land-surface parameters, Rep. 135, 23 pp., Max-Planck-Institut für Meteorologie, Hamburg, Germany, 1994.

Claussen, M., V. Brovkin, A. Ganopolski, C. Kubatzki, and V. Petoukhov. Modeling global terrestrial vegetationclimate interaction, Pholos. Trans. R. Soc. London, Ser. $B, 353,53-63,1998$.

deNoblet, N., I.C. Prentice, S. Jousaume, D. Texier, A. Botta, and A. Haxeltine, Possible role of atmospherebiosphere interactions in triggering the last glaciation, Geophys. Res. Lett.. 23. 3191-3194, 1996.

Dickinson, R.E., ('hanges in land-use, in Clımate System Modelling, edited by K.E. Trenberth, pp. 689-700, Cambridge Univ. Press. New York. 1992.

Drazın, P.G., and W.H. Reid. Hydrodynamıc Stability, 527 pp., Cambridge Univ. Press, New York, 1981.

Eltahir, E.A.B., and C. Gong, Dynamics of wet and dry years in West Africa, J. Clım., 9, 1030-1042, 1996.

Emanuel, K.A., Atmospheric Convection, 580 pp., Oxford Univ. Press, New York, 1994.

Foley, J.A., The sensitivity of the terrestrial biosphere to climatic change: A simulation of the middle Holocene, Global Brogeochem. Cycles, 8, 505-525, 1994.

Foley. J.. J.E. Kutzbach. M.T. Coe. and S. Levis. Feedbacks between climate and boreal forests during the Holocene epoch, Nature, 371, 52-54, 1994.

Gallimore, R.G., and J.E. Kutzbach, Role of orbitallyinduced vegetative changes on incipient glaciation, $\mathrm{Na}$ ture, 381, 503-505, 1996.

Ghil, M., Climate stability for a Sellers-type model, J. Atmos. Sca., 33, 3-20, 1976.

Ghil, M., Deceptively-simple models of climatic change, in Climate and Geoscrences, edited by A. Berger, S. Schneider, and J.C. Duplessy, pp. 211-240, Kluwer Acad., Norwell, Mass., 1989.

Gutman, G., On modeling dynamics of geobotanic stateclimate interaction, J. Atmos. Sci., 43, 305-306, 1985.

Held, I.M., and M.J. Suarez, Simple albedo feedback models of the ice cape, Tellus, 36,613-628, 1974.

Hoelzmann, P., D. Jolly, S.P. Harrison, F. Laarif, R. Bon- nefille, and H.-J. Pachur, Mid-Holocene land-surface conditions in northern Africa and the Arabian Peninsula: A data set for the analysis of biogeophysical feedbacks in the climate system, Global Biogeochem. Cycles, 12, 35-52, 1998.

Holdridge, L.R., Determination of world plant formations from simple climate data, Science, 105, 367-368, 1947.

Houghton, J.T., B.A. Callander, and S.K. Varney (Eds.), Climate Change 1992: Supplementary Report to the IPCC Scientific Assessment, Cambridge Univ. Press, New York, 1992.

Hubbard, J.H., and B.H. West, Differential Equations: A Dynamical Systems Approach, Higher Dimensional Systems, Springer-Verlag, New York, 1995.

Kutzbach, J.E., G. Bonan, J. Foley, and S.P. Harrison, Vegetation and soil feedbacks on the response of the African monsoon to orbital forcing in the early to middle Holocene, Nature, 384, 623-626, 1997.

Kubatzki. C., and M. Claussen, Simulation of the global biogeophysical interactions during the last glacial maximum, Clım. Dyn., 14, 461-471, 1998.

Lamb, P.J., and R.A. Peppler, Further case studies of tropical Atlantic surface atmospheric and oceanic patterns associated with sub-Saharan drought, J. Clim., 5, 476-487, 1992 .

Leemans, R., and W.P. Cramer, The IIASA database for mean monthly values of temperature, precipitation and cloudiness on a global terrestrial grid, Research rep. $R R$ 91-18. Int. Inst. for Appl. Syst. Anal., Laxenburg, Austria, 1991.

Lieth, H.. Modeling the primary productivity of the world, in Primary Productivity of the Biosphere, edited by $\mathrm{H}$. Lieth and R.H. Whittaker, pp. 237-263, Springer-Verlag, New York, 1975.

Ll, Z.-X., K. Ide, H. Le Treut, and M. Ghil, Atmospheric radiative equilibrı in a simple column model, Clim. Dyn. 13, 432-440, 1997.

Neftel, A., H. Friedli, E. Moor, H. Lotscher, H. Oeschger, U. Siegenthaler, and B. Stauffer. Atmospheric carbon dioxide concentration - Historical record, Siple station, in Trends 9.3: A Compendium of Data on Global Change, Carbon Dioxide Info. Anal. Cent., Oak Ridge Natl. Lab., Oak Ridge, Tenn., 1993.

North, G.R., R.F. Cahalan, and J.A. Coakley Jr., Energy balance climate models, Rev. Geophys., 19, 91-121, 1981

Olson, J., J.A. Watts, and L.J. Allison, Major world ecosystem complexes ranked by carbon in live vegetation: A database, CDIAC Numerical Data Collection, NDP-017, 164 pp.. Oak Ridge Natl. Lab., Oak Ridge, Tenn., 1985.

Petoukhov, V., Zonal climate model of heat and moisture exchange in the atmosphere over underlying layer (in Russian), in Physacs of the Atmosphere and Problem of Cl2mate Change, edited by G.S. Golitsyn and A.M. Yaglom, pp. 8-41, Mir Publishers, Moscow, 1980.

Petoukhov, V., and A. Ganopolski, A set of climate models for integrated modelling of climate change impacts, II A 2.5-dimensional Dynamical Statistical Climate Model (2.5-DSCM), Working pap. WP-94-39, Int. Inst. for Appl. Syst. Anal., Laxenburg, Austria, 1994.

Post, W.M., A.W. King, and S.D. Wullschleger, Historical variations in terrestrial biospheric carbon cycle, Global Brogeochem. Cycles, 11, 99-109, 1997.

Prentice, I.C., W. Cramer, S.P. Harrison, R. Leemans, R.A. Monserud, and A.M. Solomon, A global biome model based on plant physiology and dominance, soil properties and climate, J. Biogeography, 19, 117-134, 1992.

Robinson, C., Dynamical Systems: Stability, Symbolic Dynamics, and Chaos, 468 pp., CRC Press, Boca Raton, Fla., 1995. 
Roeckner, E., et al., Simulation of the present-day climate with the ECHAM model: Impact of model physics and resolution, rep. 93, 171 pp., Max-Planck-Institut für Meteorologie, Hamburg, Germany, 1992.

Saltzman, B., Paleoclimate modeling, in Paleoclimate Analysis and Modeling, edited by A.D. Hecht, pp. 341-396, John Wiley, New York, 1985.

Sellers, W.D., A climate model based on the energy balance of the Earth-atmosphere system, J. Appl. Meteorol., 8, 392-400, 1969

Svirezhev, Y.M., and V.P. Passekov, Fundamentals of Mathematical Evolutionary Genetics, 365 pp., Kluwer Acad., Norwell, Mass., 1990.

Svirezhev, Y., and W. von Bloh, A minimal model of interaction between climate and vegetation: Qualitative approach, Ecol. Modell., 92, 89-99, 1996

Texier, D., N. deNoble, P.S. Harrison, A. Haxeltine, D. Jolly, S. Joussaume, F. Laarif, I.C. Prentice, and P. Tarasov, Quantifying the role of biosphere-atmosphere feedbacks in climate change: Coupled model simulations for 6000 years BP and comparison with palaeodata for northern Eurasia and Africa, Clim. Dyn., 13, 865-882, 1997.

Woodward, F.I., Climate and Plant Distribution, 174 pp., Cambridge Univ. Press, New York, 1987.

Zheng, X., and E.A.B. Eltahir, The response to deforestation and desertification in a model of West African monsoon, Geophys. Res. Lett., 24, 155-158, 1997.

V. Brovkin, M. Claussen, A. Ganopolski, and V. Petoukhov, Potsdam-Institut für Klimafolgenforschung, Postfach 601203, 14412 Potsdam, Germany, (e-mail: victor@pikpotsdam.de; claussen@pik-potsdam.de; andrey@pikpotsdam.de; petukhov@pik-potsdam.de)

(Received April 2, 1998; revised August 20, 1998; accepted August 25, 1998.) 